\title{
SHARENTING: Literature Review
}

[0] : 10.53358/16อas.V3i2.628

Jorge Patricio Salgado Silva, Jefferson Mauricio Villota Trejo, Dilan Rivaldo Ramírez Coral, Víctor Hugo Terán Ba-

llesteros

1 Faculty of Engineering in Applied Sciences, Software Engineering,

North Technical University,

Ibarra, Ecuador

jpsalgados1@utn.edu.ec,jmvillotat@utn.edu.ec,drramirezc@utn.edu.ec,vhteranb@utn.edu.ec

\section{RESUMEN}

Abstract. The sharenting practice, or the sharing of one's parenting and children online, has become a popular topic of critical focus that decries it as an exploitative disregard for children's privacy and rights. Sharenting is becoming an increasingly common practice, putting children's safety and privacy at risk. This phenomenon is a response to the behavior of family members who share images of minors on the Internet. On the contrary, the degree of Internet addiction is a current problem in modern society, and it has begun to be related to low self-control on the part of adults. This current article aims to highlight some of the most pervasive concerns about the loss of privacy, and the pain that inappropriate information sharing practices can cause to parents and children.

Keywords: Parents, Sharenting, Inappropriate, posts, Child development, social networks. 


\section{Introducción}

The first thing to consider is the meaning of the word "sharenting", as it's well- known this is a term in English that comes from the fusion of two words share (share) and parenting (upbringing or parenting) [1].

This concept can be understood as the fact of sharing the upbringing of a child from birth and continues with its development through the most popular social networks such as Facebook and Instagram. This practice has become so common that the British dictionary, Collins included it on it pages in 2016. [2]

As this practice has become more usual, it has generated different opinions, it has been divided between people who say that this practice about exposing a child to the world of the internet and people who think that absolutely nothing happens. [3]

Having faced this, each of the opinions that should be handle with kid gloves, although it is very normal for a mother to upload a photo with her child wearing diapers, there is a risk when before she is 4 years, she may have more than 1500 photos uploaded and available on social networks [4].

This is usually overlooked, but it must be considered that the fact that social networks are "public" means that any type of person can have access to them, without knowing their clear intentions. [5]

The objective of this essay is to show all the aspects of this problem that concerns us, since all the world social networks have become a routine. This issue will be developed focusing on our reality, we are a country that consumes the most social. 


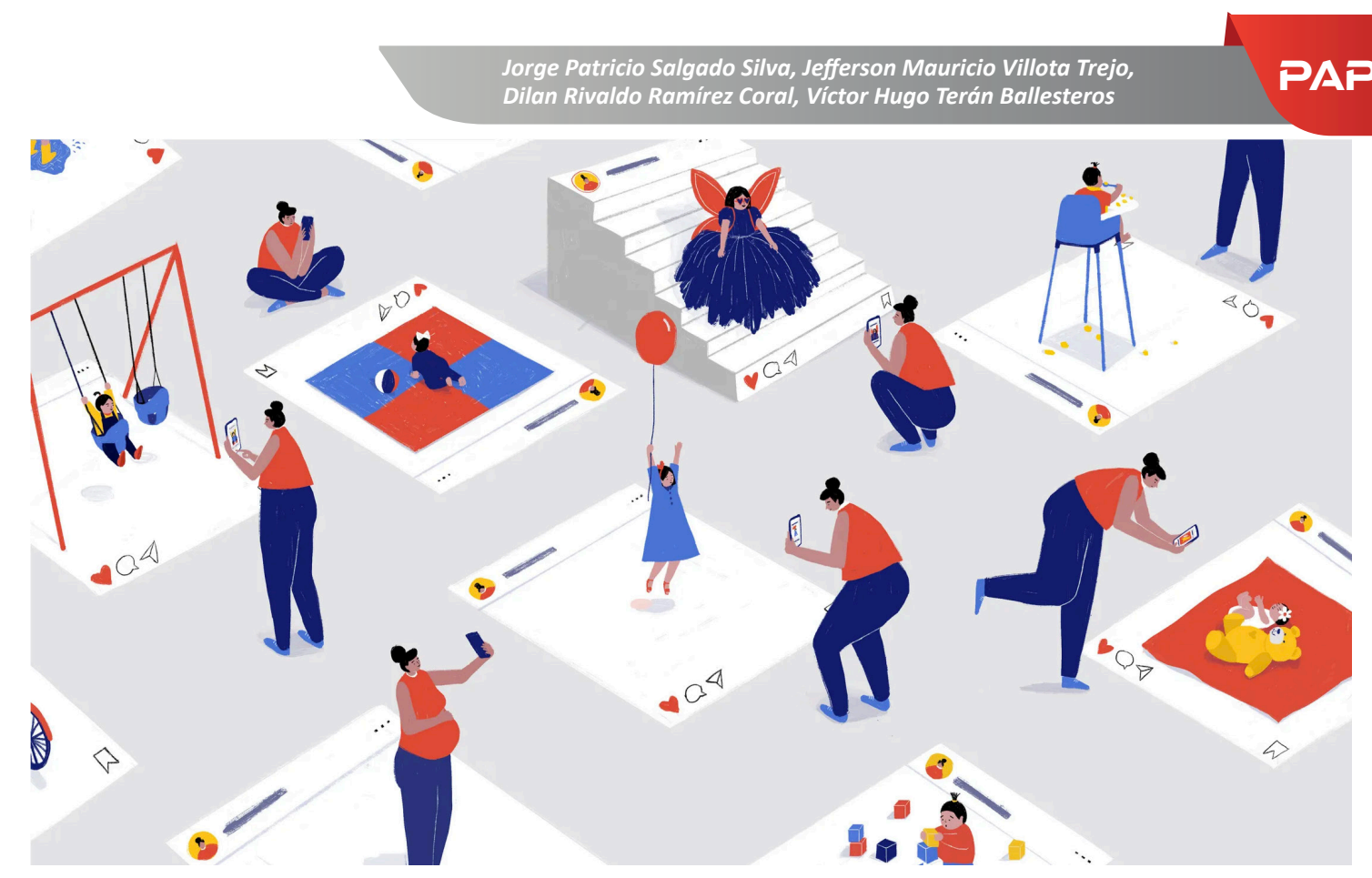

Fig. 1. Maya Ish-Shalom. Sharenthing (2019). The New Yorker, New York. Source: https://www.newyorker. com/culture/cultural-comment/instagram-facebook-and-the-perils-of-sharenting

\section{Development}

What is sharenting?

Every single day as technology advances, we find ourselves even closer to each other, either due to the reduction in transport times or through a digital medium which now everyone is interested in, that uses hardware and software that has been improved over the years to reach a point where communication takes fractions of seconds, the letters are digital, the photos and albums, among many other things that have been changed into software. [7]. [8]. [9]. [10].

This entire digital revolution has brought with it problems such as Sharenting, also known as overshareting, which describes an attitude that is becoming more and more common and whose protagonists are parents, uncles, and grandparents. Or, rather, the protagonists are the children, but those who carry out the action are the adults. Do you already know what it means? Neither more nor less than all the photos and videos that adults with the best intention in the world upload of their children, nephews, and grandchildren to Social Networks. Of course, without their approval and many times, without the children being even conscious. But before keeping on with this practice, our group is going to tell you what the risks are and why you shouldn't do it. [7], [8] [9], [10].

How does sharenting work?

Sharenting works as a practice carried out by parents to share personal information or photographs of their children on social networks. This is the first step in creating a digital identity for these minors, which can be created even before they are born. [11]

Most parents act with the best intentions when sharing personal information and photos of their children in the digital environment. Many times, it is up to parents decide appropriately when it is good to share certain information about their family, but at other times it is very difficult to share information without knowing the consequences it will probably have in the future. [11] 
In turn, there is the risk of identity theft of the minor and the possibility that these images will be shared on sites that promote pedophilia. Thus, sharenting is one of the causes of the lack of information and training on the use of networks and in on privacy and online security. [12]

"In 2016 an Austrian teenager sued her parents for refusing to delete the 500 photos they had posted on Facebook of her as a child, which she was aware of when she opened her own profile at the age of 14 and confirmed that her pictures were all available on her patents' profiles and exposed to all their 700 "friends". [10]

It is important to remember that privacy is a child's right, as well as their online identity. A series of recommendations has been published to provide parents or patients' caregivers to help them in the proper management of the information they post on social media:

They should get familiar themselves with the privacy policies of the sites where they share information.

Notifications should be configured to alert when your child's name appears in search engines (Google alerts).

Parents who choose to share information about their children's health problems or clinical conditions should consider opting to do so anonymously.

Generated problems and economic losses

With the integration of social networks, the excessive use of the Internet has skyrocketed, which is caused by the impulse and the need to always be connected to the network. According to some studies led by McAfee in 2018,30\% of the parent's upload photos of their children to the web every day. Therefore, we find current problems in full increase. [14]

However, Sharenting creates a fingerprint that is maintained throughout life and creates privacy concerns related to the data protection interests of the minors. It means that family members often compromise privacy of children and place them without their consent in public view. And most of the problems start from the content of public photos, which show minors naked or semi-naked, in a bathing suit or exposing sensitive information. [14]

Therefore, adults generally do not consider the other person's point of view, since photos provide sensitive information that can make the affected person feel ashamed and frustrated. Not forgetting the risks associated with the publication of many photos, making it easy for cybercriminals to steal images and in worst of the cases, identity theft and posting of your image on pornography websites childish. [13]

This creates additional problems. Since, in certain circumstances, these images can spread massively or become memes, using images of minors as objects of grace and / or mockery. [15]

Another big problem today is the large-scale Sharenting carried out by youtubers or instagramers parents. Not only do they share privacy and personal data children, but also use it as an advertising theme to show what the brands send, which is close to labor exploitation. Children can get toys free, brand sponsorship and millions of followers. [16] 
As in the case of Ryan Toy Review in the United States, which had a turnover in 2019 close to $\$ 20$ million just for playing with toys in front of a camera. What causes that the child spends his free time on the family channel, which would increase his educational routine childish. At the same time, more and more voices are denouncing some type of child exploitation behind children YouTubers. These exposed children are not artists. They are normal children, and a complementary activity has been imposed on them that can produce benefits. [16]

There have been many verdicts across Europe condemning parents to delete photos of their children posted on social media. For example, in France, regulations impose a maximum of 1 year in prison and a fine of up to 45,000 euros to parents who publish images or private data of your children. [17]

\section{CONCLUSION}

Sharing images of our loved ones with other people has been carried out since the origins of photography, which has led us to make this part of our culture. However, in recent years it has evolved the way of teaching photography to the closest people. It has changed from sharing that special image in person which Used to be kept in a wallet or a physical album, to share it digitally on social media to a vastly larger audience and unknown people, encouraging pedophilia or increased identity theft, therefore, that we must be aware of these risks and act under privacy policies.

We can say that it is believed that, beyond the legal protection of rights, it is necessary that civil society actors and state agencies in charge of ensuring the protection of children's rights carries out awareness campaigns aimed at parents to prevent harm not wanted or wanted to the rights of their children, when sharing information in internet and on their social networks. Since it could have great consequences if this information is misused.

We can say that parents should avoid sharing privacy and life the personal children's life on social media as well as adults should avoid share personal or private information on the Internet or at least verify that this data will not affect anyone else in any way. In this regard I say that parents must act responsibly and expect the minor to be the proper age and mainly the appropriate training to decide what content is suitable to publish to associate with their digital identity and what cannot be published. Thus, parents are the responsible of providing this education and guidance as exactly as they do in other areas of life.

This year has been a bit chaotic since we are on the brink of passing a historical event such as the pandemic, this fact has generated a technological change that according to experts, it had to occur in the next 10 or 15 years but it happened in two years. This same fact has generated an overexposure of how we live from day to day, since social networks were used to a great extent to spend time. The problem is generated when people have not measured the consequences that this generates, I believe that new generations should be nurtured with the learning and experience that has been obtained and specially to avoid all the mistakes that are being committed.

In recent years, times have been changing, and what was once an exceptional and complex luxury, today it is a daily, accessible, and fast action. We take frequent photographs, especially if there are minors in the home. Afterwards, it is difficult to resist sharing them. It is usual to see how in digital media images of babies, children and adolescents abound, and it should be noted that social networks have become a photographic album for the public, with images that reflect the days of the users and moments important like the birth of a baby. 


\section{REFERENCES}

J. R. Ubieto, "Del padre al iPad: familias y redes de la era digital.," in Del padre al iPad: familias y redes de la era digital., Barcelona, NED, 2019, p. 198.

A. Siibak and K. Traks, "Ingenta Connect," 1 April 2019. [Online]. Available: https://www. ingentaconnect.com/content/intellect/cjcs/2019/00000011/00000001/art00007. [Accessed 5 Noviembre 2021].

P. Otero, "Sap," 2017. [Online]. Available: http://dx.doi.org/10.5546/aap.2017.eng.412.

B. Mundo, "Qué es el "sharenting" y por qué deberías pensártelo dos veces antes de compartir la vida de tus hijos en redes sociales," 23 Mayo 2018. [Online]. Available: https://www.bbc.com/mundo/noticias-44210074. [Accessed 5 Noviembre 2021].

D. F. d. Marcos, "El libro definitivo sobre las redes sociales: calves para padres y educadores," in El libro definitivo sobre las redes sociales: calves para padres y educadores, Madrid, España, Wolters Kluwer, 2021, p. 205.

I. D. Maella Botero, "unizar.es," 2020. [Online]. Available: https://zaguan.unizar.es/ record/97735/files/TAZ-TFG-2020-4706.pdf.

M.W. K. H.W. H. Karen Verswijvel, "Sharenting, is it a good or a bad thing? Understanding how adolescents think and feel about sharenting on social network sites," Available: https://www.sciencedirect.com/science/article/pii/S0190740919303482. [Accessed 5 Noviembre 2021].

F. J. Hinojo Lucena, I. Aznar Díaz, M. P. Cáceres Reche, J. M. Trujillo Torres and J. M. Romero Rodríguez, "revistacomunicar," 01 julio 2020. [Online]. Available: https:// doi.org/10.3916/C64-2020-09.

A. G. GARCÍA, "lalibreria.upv.es," 0803 2021. [Online]. Available: https://gdocu.upv.es/ alfresco/service/api/node/content/workspace/SpacesStore/83afca07-6732-463ab7cb-f0101a4acd01/6656.pdf?guest=true.

C. R. Fernández Tortolero and J. L. Mendoza Márquez, "academia.edu," [Online]. Available: https://www.academia.edu/download/55788380/EL_SHARENTING_Y_ SUS_IMPLICACIONES_EN_LA_IDENTIDAD_DIGITAL.pdf.

M. S. Damkjaer, "Digitala Vetenskapliga Arkivet," 9 Marzo 2021. [Online]. Available: https:// www.diva-portal.org/smash/record.jsf?pid=diva2\%3A1535913\&dswid=8619. [Accessed 5 Noviembre 2021].

C. A. COBAS, "LA PROTECCIÓN JURÍDICA DEL MENOR EN INTERNET. ESPECIAL PROTECCIÓN EN LAS REDES SOCIALES," in LA PROTECCIÓN JURÍDICA DEL MENOR EN INTERNET. ESPECIAL PROTECCIÓN EN LAS REDES SOCIALES, León (España), Tesis de Grado Universidad de León, 2015, p. 47.

J. C. Belén Hernández, "El país," 27 Marzo 2021. [Online]. Available: https://elpais. com/planeta-futuro/2021-03-28/esto-es-lo-que-una-red-wifi-puede-hacer-por-laeducacion-en-la-pandemia.html. [Accessed 5 Noviembre 2021]. 
T. Baiget, "El Profesional de la Información," in El Profesional de la Información, León, España, 2020, p. 587.

L. M. Ángel Cepda, Ciberpadres 2.0. seguridad en la red para la familia, Bogotá: Paulinas, 2019.

S. L. Alicia Blum-Ross, "Taylor and Francis Online," 17 Abirl 2017. [Online]. Available: https://www.tandfonline.com/doi/abs/10.1080/15405702.2016.1223300. [Accessed 5 Noviembre 2021].

"Sharenting: Adicción a Internet, autocontrol y fotografias online de menores," in Sharenting: Adicción a Internet, autocontrol y fotografias online de menores, Madrid, Revista Científica de Educomunicación, 2020, p. 99. 


\section{Q e e \\ Facultad de Ingeniería en Ciencias Aplicadas}

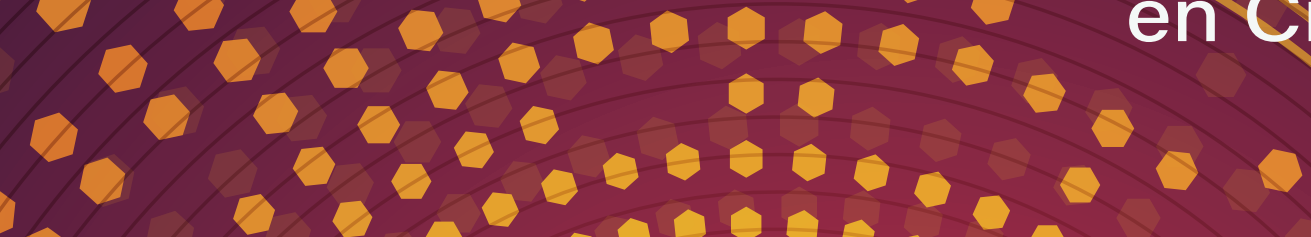

9000.

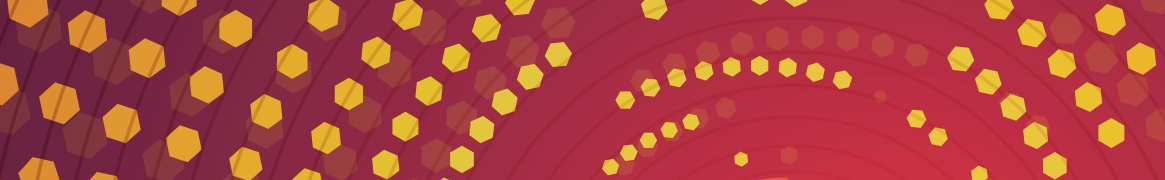

$0,0.0: 8 . \div 0$

$0,0: 8:: 8: \overline{1}$

$0,0:::: \vdots: 0$

$00::: 8:$

$100: \%: \%$

FICA: - UTN

IBARRA-ECUADOR 200.90 .0 1000000

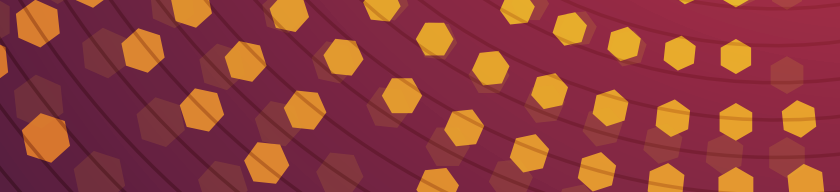
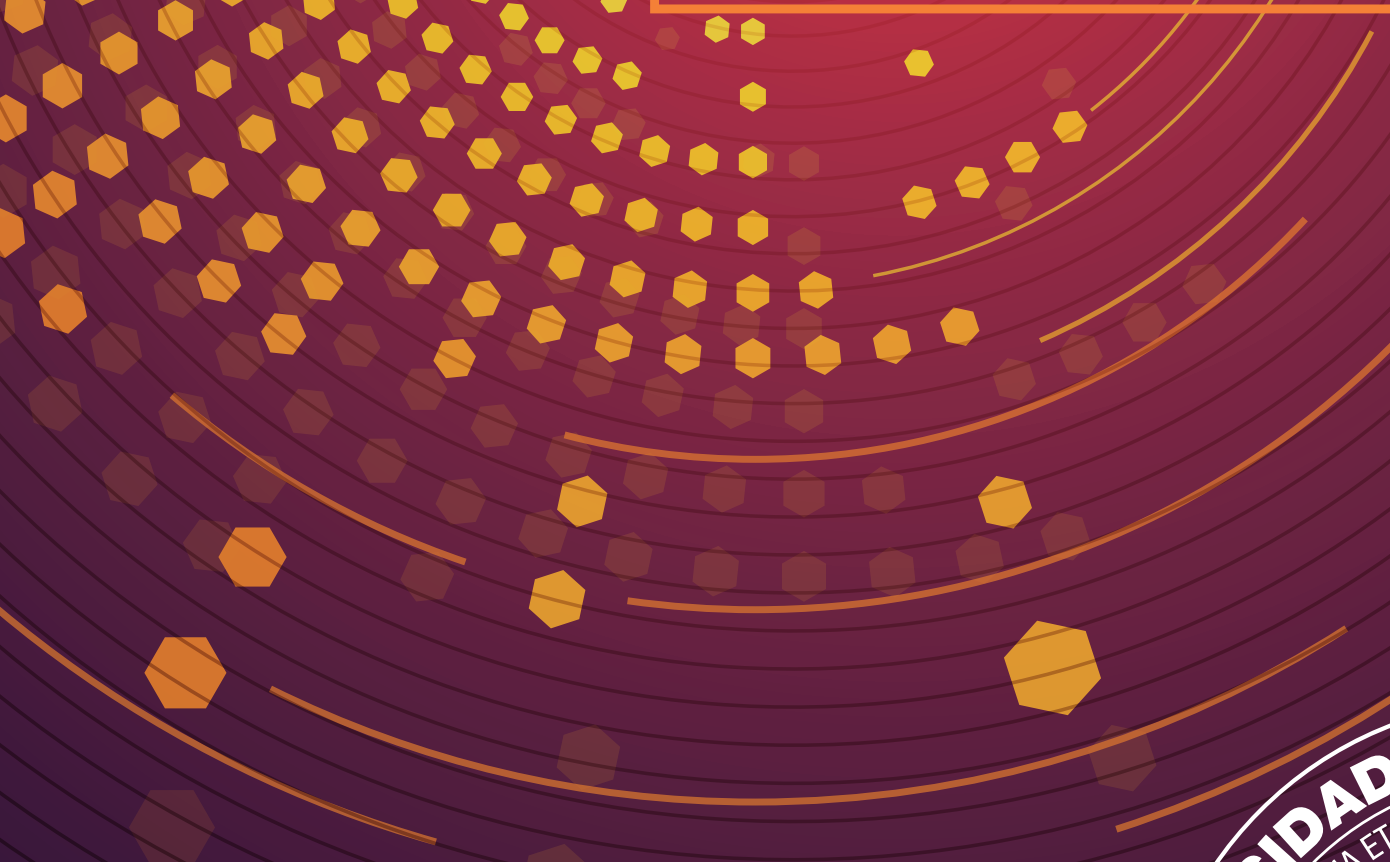